\title{
Türkiye'de Leptoglossus occidentalis Heidemann, 1910 (Hemiptera: Coreidae) üzerine biyolojik gözlemler, parazitoitleri ve yayılışına katkılar
}

Biological observations on Leptoglossus occidentalis Heidemann, 1910 (Hemiptera: Coreidae) in Turkey and contributions to its parasitoids and distribution

\section{Şükran OĞUZOĞLU'}

Mustafa AVCI ${ }^{1}$

${ }^{1}$ Isparta Uygulamalı Bilimler Üniversitesi, Orman Fakültesi, Isparta

Sorumlu yazar (Corresponding author) Şükran OĞUZOĞLU

sukranoguzoglu@sdu.edu.tr

Geliş tarihi (Received)

03.04.2019

Kabul Tarihi (Accepted)

30.05.2019

Atıf (To cite this article): OĞUZOĞLU, S, AVCI, M . (2020). Türkiye'de Leptoglossus occidentalis Heidemann, 1910 (Hemiptera: Coreidae) üzerine biyolojik gözlemler, parazitoitleri ve yayılışına katkılar. Ormancılık Araştırma Dergisi, 7 (1), 9-21.

DOI: https://doi.org/10.17568/ogmoad.548950

\section{$\ddot{O} z$}

Bu çalışmada, Leptoglossus occidentalis Heidemann, 1910 (Hemiptera: Coreidae)'in ülkemizde yeni tespit edildiği alanlar, arazi ve laboratuvardaki biyolojik gözlemler ve parazitoit türleri verilmiştir. Tür, 2016 yılında Isparta'da, 2017'de Burdur'da, 2018 yılında ise Kastamonu, Bilecik, Afyonkarahisar ve Muğla illerinde ilk kez tespit edilmiştir. Dört yıllık (2016-2019) arazi gözlemleri sonucunda türün iki generasyona sahip olduğu düşünülmektedir. Arazide kışlayan erginler haziran ayı başında yumurta bırakmaya başlamış ve beş nimf dönemini haziran-ağustos aylarında tamamlamıştır. Ağustos ayı başında birinci generasyona ait ilk erginler ve yumurtalar görülmüştür. Nimf dönemleri ağustos-ekim aylarında tamamlanmış ve eylül-ekim aylarında ikinci generasyona ait erginler görülmüştür. Laboratuvar koşullarında yumurta ve toplam nimf dönemlerinin ortalama süreleri 7,44 ve 47,19 gün olarak bulunmuştur. Bu çalışma ile ülkemizde ilk kez türün parazitoitleri olarak Anastatus bifasciatus (Geoffroy, 1785) (Hymenoptera: Eupelmidae) ve Ooencyrtus telenomicida (Vassiliev) (Hymenoptera: Encyrtidae) belirlenmiştir. O. telenomicida, L. occidentalis'in parazitoiti olarak dünyada ilk kez tespit edilmiştir.

Anahtar kelimeler: Yabancı istilacı tür, biyoloji, yumurta parazitoiti, Türkiye.

\begin{abstract}
In this study, parasitoid species of Leptoglossus occidentalis Heidemann, 1910 (Hemiptera: Coreidae), new localities of the species which were detected in Turkey and the biological observations in the field and in the laboratory were addressed. The species was detected in Isparta in 2016, in Burdur in 2017, and in Kastamonu, Bilecik, Afyonkarahisar and Muğla in 2018 for the first time. As a result of fouryears (2016-2019) field observations, it was thought that the species has two generations per year. Overwintered adults laid eggs in June and five nymphal stages were completed in June-August in the field. The first adults of the first generation and eggs were seen at the beginning of August. Nymphal stages were completed in August-October, and adults of the second generation were seen in September and October. The mean duration of egg and total nymphal stages were found as 7,44 and 47,19 days under laboratory conditions. In this study, the parasitoids of the species Anastatus bifasciatus (Geoffroy, 1785) (Hymenoptera: Eupelmidae) and Ooencyrtus telenomicida (Vassiliev) (Hymenoptera: Encyrtidae) were determined for the first time in our country. O. telenomicida was identified as a parasitoid of $L$. occidentalis for the first time in the world.
\end{abstract}

Keywords: Invasive alien species, biology, egg parasitoid, Turkey. 


\section{Giriş}

Leptoglossus occidentalis Heidemann, 1910 (Hemiptera: Coreidae), iğne yapraklı ağaçların tohumlarındaki öz suyu ile beslenen önemli bir kozalak zararlısıdır. Kuzey Amerika orijinli bir tür olup 1910 yılında tanımlanmıştır (Heidemann, 1910). İkinci Dünya Savaşı'ndan sonra Orta ve Doğu Amerika'ya yayılmıştır (Koerber, 1963; Gall, 1992; Schoettle ve Negron, 2001). Tür, Avrupa'ya 1999 yılında geçerek ilk kez İtalya'da görülmüş (Villa ve ark., 2001) ve hızlı bir yayılış yaparak hemen hemen tüm Avrupa ülkelerinde tespit edilmiştir (Barta, 2009; Petrakis, 2011; Fent ve Kment, 2011; Putshkov ve ark., 2012; Van der Heyden, 2018). Asya kıtasında türün ilk kaydına 2008 yılında Japonya'da (Ishikawa ve Kikuhara, 2009) rastlanmış, daha sonra 2010'da Çin (Zhu ve ark., 2014), 2012'de Güney Kore (Yoon ve ark., 2012), 2013'te Rusya (Gapon, 2013), 2015'te Lübnan'da (Nemer, 2015) ve 2018 yilında ise Kazakistan'da (Barclay ve Nikolaeva, 2018) varlığı bildirilmiştir. L. occidentalis, Afrika kıtasında ilk kez 2011 yılında Tunus'ta (Ben Jaama ve ark., 2013), daha sonra 2015 yılında Fas'ta (Gapon, 2015) saptanmıştır. Güney Amerika'da türün ilk kaydı ise 2017 yılında Şili'de yapılmıştır (Faúndez ve ark., 2017). Bu istilacı tür, çoğunlukla çam türleri olmak üzere birçok ibreli ağaç türünde görülmektedir. Günümüze kadar Pinus armandii, $P$. brutia, $P$. coulteri, $P$. contorta, $P$. densiflora, $P$. flexilis, $P$. griffithii, $P$. halepensis, $P$. jeffreyi, P. lambertiana, P. monticola, P. mugo, P. nigra, $P$. pinea, $P$. pinaster, $P$. ponderosa, $P$. radiata, $P$. resinosa, $P$. rigida, $P$. sabiniana, $P$. strobus, Pinus $x$ schwerinii, P. sylvestris, Pseudotsuga menziesii, P. macrocarpa, Tsuga canadensis, T. mertensiana, Calocedrus (=Libocedrus) decurrens, Abies concolor, A. magnifica, Picea glauca, P. excelsae, Cedrus atlantica, C. deodora, Cupressus sempervirens üzerinde zararlı olduğu tespit edilmiștir (Koerber, 1963; Gall, 1992; Bates ve ark., 2002; Vanin ve ark., 2005; Kment ve Baňař, 2008; Protić, 2008; Maltese ve ark., 2009; Barta, 2009; Kollar ve ark., 2009; Gapon, 2015; Özgen ve ark., 2017).

Leptoglossus occidentalis, Türkiye'de 2009 yılında ilk kez İstanbul-Sarıyer ve Edirne'de tespit edilmiştir (Arslangündoğdu ve Hızal, 2010; Fent ve Kment, 2011). Tür ülkemizde hızlı bir şekilde yayılmış ve 2010 yılında Kırklareli-Lüleburgaz'da (Fent ve Kment, 2011), 2011 yılında AnkaraAtatürk Orman Çiftliği ve Kızılcahamam, İstanbul-Zeytinburnu ve Edirne'de (Yıldırım ve ark., 2013; Çerçi ve Koçak, 2016), 2012 ve 2015 y1llarında İzmir'de (Hızal ve İnan, 2012; Çerçi ve Koçak, 2016), 2011 ve 2012 yıllarında Balıkesir'de (Dursun, 2016), 2016'da Isparta-Gölcük Tabiat Par- kı'nda (Özek ve Avc1, 2017), 2017'de Bursa'da (Parlak, 2017) ve Elazığ'da (Özgen ve ark., 2017), 2016 yılında Artvin'de (Aksu, 2018), 2017 yılında ise Isparta-Merkez, Yalvaç, Eğirdir ve Burdur-Merkez'de (Oğuzoğlu ve Avc1, 2018) yayılış gösterdiği bildirilmiştir. Ülkemizde Pinus nigra, $P$. pinea, $P$. radiata, $P$. sylvestris, $P$. brutia, Abies sp., ve $A$. concolor üzerinde görülmüştür (Arslangündoğdu ve Hizal, 2010; Hizal ve İnan, 2012; Hizal, 2012; Dursun, 2016; Özek ve Avc1, 2017; Parlak, 2017; Özgen ve ark., 2017; Aksu, 2018; Oğuzoğlu ve Avc1, 2018).

Önemli bir tohum ve kozalak zararlısı olan $L$. occidentalis genç kozalaklarda protein ve yağ içeren tohumlardan öz suyu emerek beslenmekte ve boş tohum oluşumuna neden olmaktadır. Beslenme nedeniyle genç kozalaklar olgunlaşmadan düşmektedir (Bates ve ark., 2000; Bates ve Borden, 2005; Strong, 2006; Pimpao ve ark., 2017). Türün nimf ve erginlerinin kozalak üzerinde beslenmesi esnasında hortumlarını batırdığı yerlerde reçine sızıntıları görülmektedir (Özek ve Avc1, 2017). Türün ülkemizde ekonomik açıdan zararına ilişkin ilk tespit İzmir-Bergama'da fıstık çamı sahalarında yapılmış ve önemli zarara yol açtığı bildirilmiştir (Parlak, 2017).

Ülkemizde 2009 yılında tespit edilen ve hıla yayılış alanlarını artıran bu türün ülkemizdeki biyolojisi konusunda sınırlı bilgi bulunmaktadır. Biyolojisi ve yayılışına ilişkin bilgilerin elde edilmesi ile hem türün zararı daha iyi ortaya konulabilecek hem de türün mücadelesine yönelik çalışmalar yapılabilecektir. Bu çalışmada, türün yayılış yaptığı yeni lokaliteler ile Isparta ilinde ve diğer illerden elde edilen bilgilere göre biyolojisi ve parazitoit türleri hakkında yapılan çalışma sonuçları verilmiştir. Bu türle ilgili çalışmaların ülkemizde birçok alanda yapılarak eldeki bilgilerin geliştirilmesi ve türün ülkemizdeki biyolojisinin ortaya konularak mücadelesi için gerekli bilgilerin elde edilmesi önemlidir.

\section{Materyal ve Yöntem}

Bu çalışma 2016-2019 yıllarında Isparta ili çam (Pinus spp.) ormanlarında gerçekleştirilmiştir. Ek olarak Burdur, Kastamonu, Bilecik, Afyonkarahisar ve Muğla'da da türün tespiti yapılmış ve biyolojik gözlemler kaydedilmiştir. Doğada türün görüldüğü tarih ve biyolojik dönem, konukçu ve sahaya ait bilgiler kaydedilmiştir.

Laboratuvar koşullarında türün biyolojisi üzerine gözlemler yapmak amaciyla 2018 y1lı haziran ay1 sonunda görülen bireyler laboratuvara getirilmiştir. Oda sıcaklığındaki laboratuvar ortamında üzeri 
tülle kaplı kaplara erginler ile kozalaklar konularak takibe alınmıştır. Erginler iki günde bir kontrol edilmiş ve Süleyman Demirel Üniversitesi Botanik Bahçesi'nde Pinus nigra'dan ve Gölcük Tabiat Park1'nda $P$. sylvestris'ten toplanan kozalaklar laboratuvara getirilerek kaplardaki kozalaklar iki günde bir değiştirilmiştir.

Yumurtaların bırakılma ve açılma tarihleri ile açılan ve açılmayan yumurta sayıları kaydedilmiştir. Yumurtaların ibre ucuna mesafesi ile yumurta paketi uzunluğu ölçülmüştür. Ayrıca türün yumurta bırakma davranışını ortaya koymak amacıyla her bir ibre üç eşit parçaya ayrılmış (dip, orta, uç) ve yumurta paketi merkez noktasının bu üç parçadan hangisinde kaldığı belirlenmiştir (Barta, 2016). Nimf dönemleri izlenerek nimf süreleri kayıt altına alınmıştır. Arazide görülen açılmamış yumurtalar laboratuvara getirilerek kaplara konmuş ve parazitoit çıkışı izlenmiştir. Parazitoitlerin çıkış tarihleri kaydedilmiş ve fotoğraflanmıştır. Parazitoit türlerin teşhisi Prof. George JAPOSHVILI (Tiflis Ta- rım Üniversitesi, Entomoloji Enstitüsü, Gürcistan) tarafından yapılmıştır.

\section{Bulgular}

\subsection{Morfolojisi}

Erginlerin vücutları uzun yapıda ve kırmızımtırak kahverenginde olup abdomende turuncu siyah bantlar bulunmaktadır. Tibia yaprak şeklinde, anten geniculat (dirsekli) yapıda, gözler ise belirgin siyah küre biçimindedir. Elde ettiğimiz erginlerdeki ölçümlerimize göre vücut uzunluğu 15,10-21,80 mm arasında değişmekte olup dişi erginlerde ortalama $19,10 \mathrm{~mm}(\mathrm{n}=40)$, erkek erginlerde ise ortalama 17,69 mm'dir ( $\mathrm{n}=31$ ). Proboscis (hortum) uzunluğunun dişilerde ortalama $12,00 \mathrm{~mm}$, erkeklerde ise ortalama 11,74 mm olduğu belirlenmiştir (Şekil 1, Tablo 1). Bu değerlere göre dişilerin erkeklere oranla daha uzun oldukları ve proboscis uzunluklarının da vücut uzunlukları ile doğru orantılı olduğu belirlenmiştir.

Tablo 1. Leptoglossus occidentalis'in dişi ve erkek bireylerinin vücut ve proboscis uzunluklar1 Table 1. Body and proboscis length of female and male Leptoglossus occidentalis

\begin{tabular}{lcccccc}
\hline \multirow{2}{*}{ Parametreler } & \multicolumn{3}{c}{ Dişi $(\mathrm{n}=40)$} & \multicolumn{3}{c}{ Erkek $(\mathrm{n}=31)$} \\
\cline { 2 - 7 } & Ort. $( \pm$ Sh) & Min. & Mak. & Ort. $( \pm$ Sh $)$ & Min. & Mak. \\
\hline Vücut uzunluğu $(\mathrm{mm})$ & $19,10 \pm 0,21$ & 17,20 & 21,80 & $17,69 \pm 0,20$ & 15,10 & 19,20 \\
Proboscis uzunluğu $(\mathrm{mm})$ & $12,00 \pm 0,12$ & 10,50 & 14,50 & $11,74 \pm 0,12$ & 10,50 & 13,10 \\
\hline
\end{tabular}

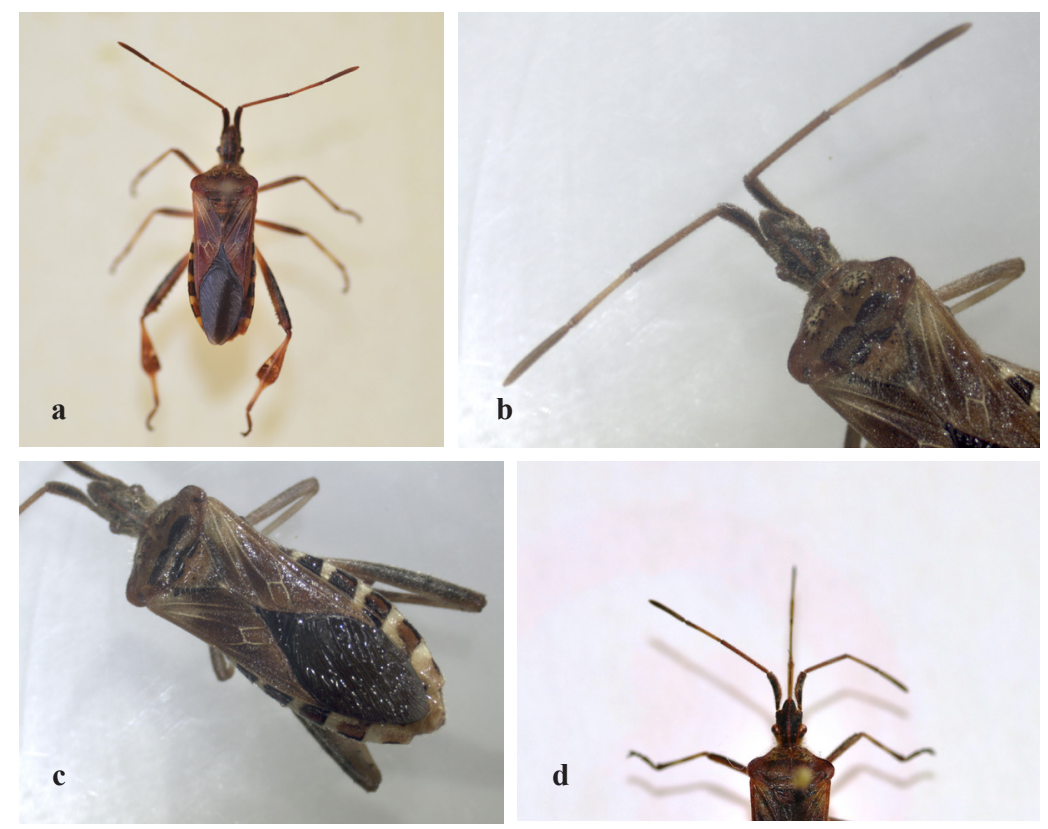

Şekil 1. Leptoglossus occidentalis ergini (a) ve türün bazı morfolojik karakteristikleri (b: anten, c: kanat, d: proboscis)

Figure 1. Adult of Leptoglossus occidentalis (a) and some morphological characteristics of the specie (b: antenna, c: wing, d: proboscis) 
Nimf evresi beş dönemden oluşmaktadır. İlk dönemde nimflerin baş ve toraksının açık kahverengi, abdomeninin ise turuncu renkte olduğu, abdomenin dorsal kısmında kahverengi lekelerin bulunduğu belirlenmiştir. İkinci dönem nimflerde baş ve toraks kısmının koyu kahverengi, abdomenin açık kızıl kahverengi olduğu ve abdomendeki dorsal lekelerin daha belirgin olduğu gözlenmiştir. Üçüncü nimf döneminde toraks ve abdomenin daha geniş olduğu ve kanatların oluşmaya başladığı tespit edilmiştir. Abdomende ikinci dönem nimflere göre bir renk değişikliği olmamış,

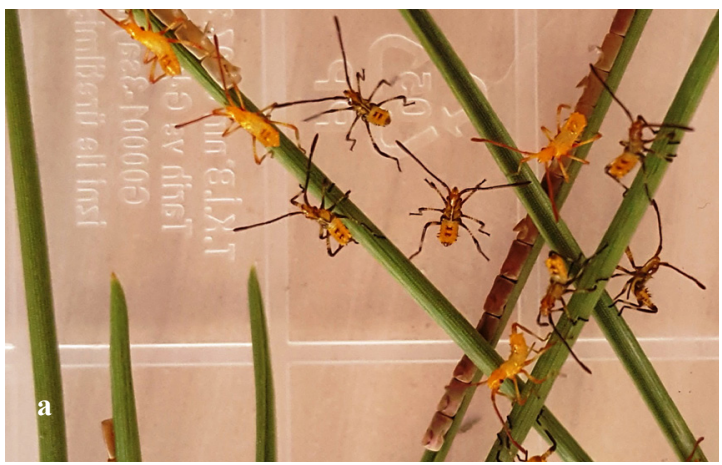

ancak arka tibia düzleşmeye başlamıştır. Dördüncü dönem nimflerin baş ve toraksının daha kızıl kahverengi, abdomenin ise kahverengi olduğu görülmüştür. Kanat örtüsü üçüncü döneme göre daha gelişmiş ve arka tibia düzleşmiştir. Beşinci dönem nimflerin ise baş, toraks ve abdomenlerinin koyu kahverengi olduğu ve arka femurda çıkıntıların oluştuğu belirlenmiştir. Ergin ve nimflerin yeni döneme geçtiklerinde sarımsı turuncu renkte olduğu, daha sonra k1zıl kahverengiye döndüğü görülmüştür (Şekil 2).

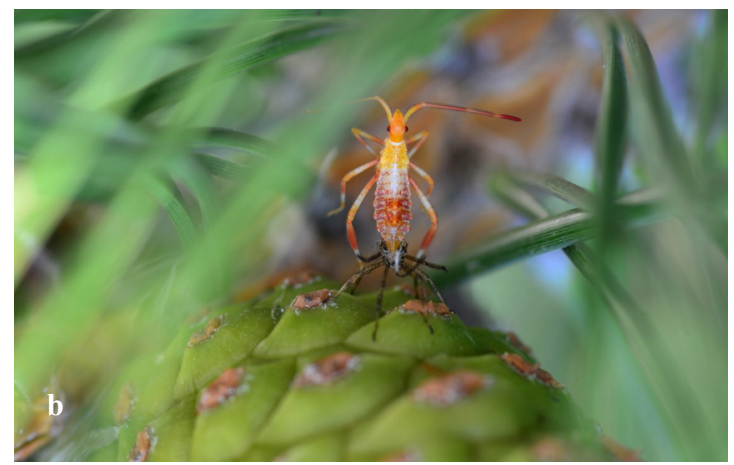

Şekil 2. Leptoglossus occidentalis'in 1. nimf bireyleri (a) ile 2. nimf dönemine geçen bireyi (b) Figure 2. First nymphs (a) and second nymph (b) of Leptoglossus occidentalis

\subsection{Türün dağılımı ve konukçuları}

Bu çalışmada, 2018 yılında Kastamonu, Bilecik, Afyonkarahisar ve Muğla illerinde türün varlığı ilk kez tespit edilmiş, Tablo 2'de türün görüldüğü tarih ve konukçuları verilmiştir. Türün nimf ve erginleri, Isparta, Bilecik ve Kastamonu'da Pinus nigra ve $P$. sylvestris, Afyonkarahisar'da P. nigra, Burdur'da $P$. brutia, Muğla'da ise $P$. pinea kozalaklarında beslenme esnasında tespit edilmiştir (Şekil 3).

Tablo 2. Leptoglossus occidentalis'in tespit edildiği yeni lokaliteler Table 2. New localities where Leptoglossus occidentalis was found

\begin{tabular}{lcl}
\hline Toplandığ1 yer & Görüldüğü tarih & Konukçu \\
\hline Kastamonu/Merkez & 22.06 .2018 & Pinus nigra, P. sylvestris \\
Bilecik/Merkez & 03.07 .2018 & Pinus nigra, P. sylvestris \\
Afyonkarahisar/Merkez & 07.09 .2018 & Pinus nigra \\
Muğla/Fethiye & 16.10 .2018 & Pinus pinea \\
\hline
\end{tabular}
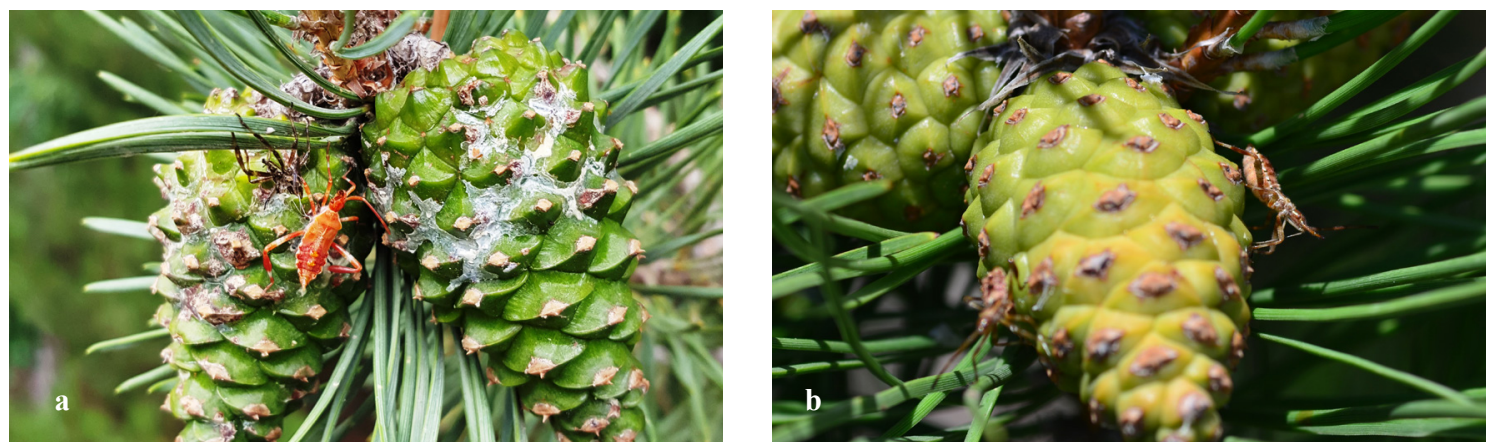

Şekil 3. Pinus sylvestris (a) ve P. nigra (b) üzerinde beslenen nimfler

Figure 3. Nymphs feeding on Pinus sylvestris (a) and P. nigra (b) 


\subsection{Türün biyolojisine ilişkin tespitler}

\subsubsection{Arazi tespitleri}

Leptoglossus occidentalis'in Isparta'da Ağustos 2016'da ilk kez tespit edilmesi ile türün yayılışı ve biyolojisi takip edilmeye başlanmıştır. Gözlemler çoğunlukla Isparta ili çam ormanlarında yapılmış, ayrıca Burdur, Bilecik, Kastamonu, Afyonkarahisar, Muğla'dan da veriler toplanmıştır. Türün 2016, 2017, 2018 ve 2019 yıllarında tespit edildiği yerler, bu yerlere ait yükselti, tarih, konukçu bitki türü ve türün biyolojik dönemine ait bilgiler kaydedilmiş ve aşağıda verilmiştir (Tablo 3).

Tablo 3. Leptoglossus occidentalis'in belirlendiği lokalite, yükselti, tarih, konukçu ve biyolojik dönemleri Table 3. Localities, altitudes, dates, hosts and biological stages of Leptoglossus occidentalis

\begin{tabular}{|c|c|c|c|c|}
\hline Lokalite & $\begin{array}{l}\text { Yükselti } \\
\quad(\mathrm{m})\end{array}$ & Tarih & Konukçu Bitki & Biyolojik Dönem \\
\hline Isparta-Büyükgökçeli Köyü & 926 & 02.08 .2016 & P. nigra & Ergin, Nimf \\
\hline Isparta-Gölcük Tabiat Parkı & 1393 & $11-12.08 .2016$ & P. nigra-P. sylvestris & Ergin, Nimf \\
\hline Isparta-SDÜ Yerleşke & 1009 & 19.08.2016 & P. nigra & Ergin, Nimf, Yumurta \\
\hline Isparta-Merkez & 1025 & 21.08.2016 & P. nigra & Ergin, Nimf, Yumurta \\
\hline Isparta-SDÜ Yerleşke & 1009 & 23.08.2016 & P. nigra & 2. 3. ve 4. Nimf \\
\hline Isparta-SDÜ Yerleşke & 1009 & 08.09 .2016 & P. nigra & Ergin, 2. ve 3. Nimf \\
\hline Isparta-Gölcük Tabiat Parkı & 1389 & 08.08 .2017 & P. sylvestris & Ergin, 1. ve 2. Nimf \\
\hline Isparta-SDÜ Yerleşke & 1009 & 22.08 .2017 & P. nigra & $\begin{array}{l}\text { Ergin, Nimf, Açılmış ve } \\
\text { açılmamış yumurta }\end{array}$ \\
\hline Isparta-Yalvaç-Bahtiyar Köyü & 1100 & 13.09.2017 & P. nigra & Ergin, 1. 2. ve 3. Nimf, Yumurta \\
\hline Isparta-Eğirdir-Pazarköy & 1195 & 06.10 .2017 & P. nigra & Ergin, Nimf, Yumurta \\
\hline Burdur-Merkez & 880 & 15.10.2017 & P. nigra-P. brutia & 5. Nimf \\
\hline Kastamonu-Merkez & 813 & 22.06.2018 & P. nigra-P. sylvestris & Ergin, 1. 2. ve 3. Nimf \\
\hline Isparta-SDÜ Yerleşke & 1009 & 24.06.2018 & P. nigra & Ergin, 1. ve 2. Nimf \\
\hline Isparta-Botanik Bahçesi & 1007 & 26.06.2018 & P. nigra & $\begin{array}{l}\text { Ergin, 1. ve } 2 \text {. Nimf, Açılmış } \\
\text { yumurta, Çiftleşen erginler }\end{array}$ \\
\hline Bilecik-Merkez & 582 & 04.07 .2018 & P. nigra & Ergin, 1. 2. 3. ve 4. Nimf \\
\hline Isparta-Gölcük Tabiat Parkı & 1430 & 11.07.2018 & P. nigra-P. sylvestris & Ergin \\
\hline Isparta-SDÜ Yerleşke & 1009 & 14.07.2018 & P. nigra & 4. Nimf \\
\hline Isparta-Keçiborlu/Tekkeli & 1170 & 21.07.2018 & P. nigra & $\begin{array}{l}\text { Ergin, 3. Nimf, Açılmış } \\
\text { yumurta }\end{array}$ \\
\hline Isparta-Senirkent/Santral & 1040 & 22.07 .2018 & P. nigra-P. brutia & Ergin \\
\hline Isparta-Senirkent & 965 & 23.07.2018 & P. nigra & Ergin, 2. ve 3. Nimf \\
\hline $\begin{array}{l}\text { Isparta-Davras Kulova Yay- } \\
\text { las1 }\end{array}$ & - & 25.07.2018 & P. nigra & Ergin \\
\hline Isparta-Botanik Bahçesi & 1007 & 26.07.2018 & P. nigra & 1. Nimf \\
\hline Isparta-Gölcük Tabiat Park1 & 1430 & 29.07 .2018 & P. nigra-P. sylvestris & 2. ve $5 . \mathrm{Nimf}$ \\
\hline Isparta-Botanik Bahçesi & 1007 & 03.08 .2018 & P. nigra & 3. ve 4. Nimf \\
\hline Isparta-Eğirdir & 992 & 04.08 .2018 & P. nigra & $\begin{array}{l}\text { Ergin, Nimf, açılmış ve } \\
\text { açılmamış yumurta }\end{array}$ \\
\hline Isparta-Gölcük Tabiat Parkı & 1430 & 05.08 .2018 & P. nigra-P. sylvestris & 4. Nimf \\
\hline Isparta-Botanik Bahçesi & 1007 & 13.08.2018 & P. nigra & $\begin{array}{l}\text { Ergin, Nimf, Açılmış ve } \\
\text { açılmamış yumurta }\end{array}$ \\
\hline Isparta-Botanik Bahçesi & 1007 & 16.08 .2018 & P. nigra & 2. ve 4. Nimf \\
\hline Isparta-Botanik Bahçesi & 1007 & 26.08 .2018 & P. nigra & 3. Nimf \\
\hline Afyonkarahisar-Merkez & 1243 & 07.09 .2018 & P. nigra & Ergin, 5. Nimf \\
\hline Isparta-Eğirdir-Yuvalı köyü & 1312 & 28.09 .2018 & P. nigra & Ergin \\
\hline Isparta-Keçiborlu & 1200 & 05.10 .2018 & P. nigra & 3. Nimf, Açılmış yumurta \\
\hline Muğla-Fethiye & 29 & 16.10 .2018 & P. pinea & Ergin \\
\hline Burdur-Kent Ormanı & 880 & 20.10 .2018 & P. brutia & Ergin \\
\hline Isparta-Gönen-Gölbaşı köyü & 937 & 12.05.2019 & P. nigra & Ergin \\
\hline
\end{tabular}


Tablo 3'e göre dört yıllık gözlemler sonucunda türün biyolojik dönemlerinin bulunduğu tarihler değerlendirilmiş ve iki generasyona sahip olduğu tespit edilmiştir. Tür, 2016 ve 2017 yıllarında ağustos ayında, 2018 yılında haziran ayı sonunda, 2019 yılında ise mayıs ortasında görülmeye başlamıştır. 2017 yılının ikinci generasyonuna ait kışlayan erginler 2018 yılında haziran başı ile temmuz ortası arasında yumurta bırakmıştır. Haziran sonunda ilk bırakılan yumurtaların açılmasıyla başlayan nimf dönemi (1-5. nimf) temmuz ayı sonuna kadar sürmüş ve ağustos ayı başında erginler görülmeye başlamıştır. İkinci generasyona ait yumurta dönemi her üç yılda da ağustos ayında görülmüş olup 2016 ve 2017 'de ağustos ayı ortalarında, 2018 yılın- da ağustos ayının ilk haftasında tespit edilmiştir. Ancak 08 Ağustos 2017 tarihinde 1. nimf dönemine ait bireylerin görülmesi nedeniyle yumurta döneminin daha erken başladığ 1 tahmin edilmektedir. Ağustos ayı ortasından itibaren açılmamış yumurtaya rastlanmamıştır. Nimf döneminin ağustos ayının ilk haftasında başlayarak ekim ortasına devam ettiği gözlenmiştir. Eylül ve ekim aylarında türün erginleri görülmüştür (Tablo 4, Şekil 4).

\subsection{Laboratuvar tespitleri}

Laboratuvarda yumurta, nimf ve ergin dönemlerinin görüldüğü tarihler Tablo 5'te verilmiştir. İlk bırakılan yumurta ile başlayan ve nimf çıkışına kadar olan yumurta dönemi 26 Haziran'da

Tablo 4. Arazi koşullarında Leptoglossus occidentalis'in değişik biyolojik dönemlerinin görüldüğü tarihler Table 4. The dates at which different biological stages of Leptoglossus occidentalis were seen

\begin{tabular}{|c|c|c|c|c|c|}
\hline & & 2016 & 2017 & 2018 & 2019 \\
\hline \multirow{8}{*}{ 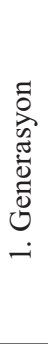 } & Ergin & - & - & 22 Haziran-25 Temmuz & 12 Mayıs \\
\hline & Yumurta & - & - & - & \\
\hline & 1. Nimf & - & - & 22 Haziran-26 Temmuz & \\
\hline & 2. Nimf & - & - & 22 Haziran-29 Temmuz & \\
\hline & 3. Nimf & - & - & 22 Haziran-03 Ağustos & \\
\hline & 4. Nimf & - & - & 04 Temmuz-05 Ağustos & \\
\hline & 5. Nimf & - & - & 29 Temmuz & \\
\hline & Ergin & 02 Ağustos & 08 Ağustos-22 Ağustos & 04 Ağustos-13 Ağustos & \\
\hline \multirow{7}{*}{ 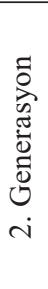 } & Yumurta & 19-21 Ağustos & 22 Ağustos & 04 Ağustos-13 Ağustos & \\
\hline & 1. Nimf & - & 08 Ağustos-13 Eylül & - & \\
\hline & 2. Nimf & 23 Ağustos-08 Eylül & 08 Ağustos-13 Eylül & 16 Ağustos & \\
\hline & 3. Nimf & 23 Ağustos-08 Eylül & 13 Eylül & 26 Ağustos-05 Ekim & \\
\hline & 4. Nimf & 23 Ağustos & - & 16 Ağustos & \\
\hline & 5. Nimf & - & 15 Ekim & 07 Eylül & \\
\hline & Ergin & 08 Eylül & 13 Eylül-06 Ekim & 07 Eylül-20 Ekim & \\
\hline
\end{tabular}
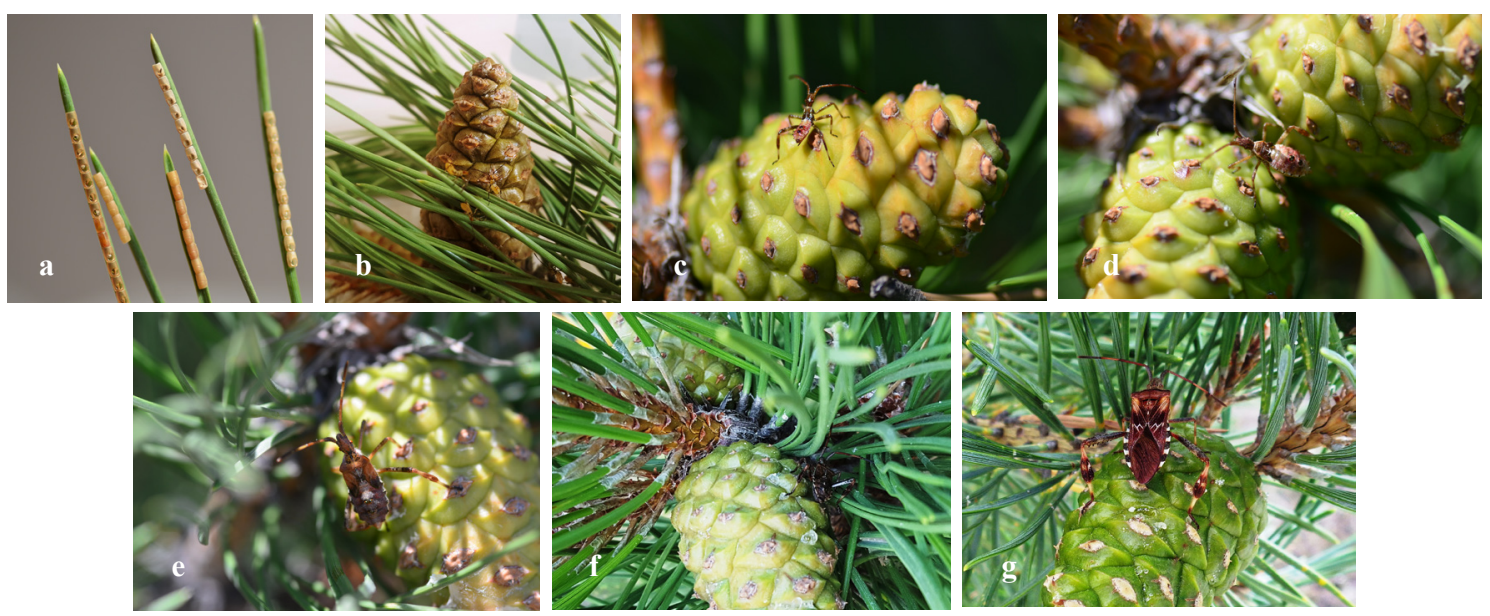

Şekil 4. Leptoglossus occidentalis'in değişik biyolojik dönemleri

(a: Yumurta, b: 1. Nimf, c: 2. Nimf, d: 3. Nimf, e: 4. Nimf, f: 5. Nimf, g: Ergin)

Figure 4. Different biological stages of Leptoglossus occidentalis

(a: Egg, b: $1^{\text {st }}$ Nymph, c: $2^{\text {nd }}$ Nymph, d: $3^{\text {rd }}$ Nymph, e: $4^{\text {th }}$ Nymph, f: $5^{\text {th }}$ Nymph, g: Adult) 
başlamış ve 14 Ağustos'a kadar devam etmiştir. Ağustos ortasından itibaren yumurta birakılmad1ğ1 belirlenmiştir. Bırakılan bir yumurtanın açılma süresi ortalama 7,44 gün olarak bulunmuştur. Birinci nimf dönemi 7 Temmuz-20 Ağustos, 2. nimf dönemi 12 Temmuz-22 Ağustos, 3. nimf dönemi 11 Ağustos-28 Ağustos, 4. nimf dönemi 20 Ağustos-6
Eylül ve 5. nimf dönemi ise 28 Ağustos-9 Eylül arasında gerçekleşmiştir. Ortalama nimf dönemleri $7,60,8,80,8,56,10,23$ ve 12,00 gün olarak belirlenmiştir. Toplam nimf dönemi ortalama 47,19 gün olarak tespit edilmiş ve 7 Temmuz'da başlayıp 9 Eylül'e kadar devam etmiştir. İlk erginler 9 Eylül tarihinde görülmeye başlanmıştır.

Tablo 5. Leptoglossus occidentalis'in laboratuvar koşullarında yumurta ve nimf dönemlerinin görüldüğü tarih aralıkları ile yaşam süreleri

Table 5. The dates at which egg and nymphal stages of Leptoglossus occidentalis were seen and their lifespan under laboratory conditions

\begin{tabular}{llccc}
\hline \multirow{2}{*}{ Yaşam dönemi } & \multirow{2}{*}{ Gelişim dönemleri } & \multicolumn{3}{c}{ Bir bireyin yaşam süresi (gün) } \\
\cline { 3 - 5 } & & Ort. & Min. & Mak. \\
\hline Yumurta & 26 Haziran-14 Ağustos 2018 & 7,44 & 6 & 8 \\
1. Nimf & 07 Temmuz-20 Ağustos 2018 & 7,60 & 7 & 9 \\
2. Nimf & 12 Temmuz-22 Ağustos 2018 & 8,80 & 8 & 10 \\
3. Nimf & 11 Ağustos-28 Ağustos 2018 & 8,56 & 8 & 10 \\
4. Nimf & 20 Ağustos-06 Eylül 2018 & 10,23 & 9 & 12 \\
5. Nimf & 28 Ağustos-09 Eylül 2018 & 12,00 & 9 & 15 \\
Toplam Nimf & 7 Temmuz-09 Eylül 2018 & 47,19 & 41 & 56 \\
Yumurta-Nimf & 26 Haziran-09 Eylül 2018 & 54,63 & 47 & 64 \\
\hline
\end{tabular}

\subsection{Yumurta bırakma davranıșı ve yumurtaların açılma oranları}

Araziden toplanan ve laboratuvarda elde edilen yumurta paketlerinin her birindeki yumurtalar say1mış ve yumurtaların açılma oranları belirlenmiştir (Tablo 6). P. nigra'dan arazide 17 (=135 yumurta), laboratuvarda 59 yumurta paketi (=461 yumurta) ve $P$. sylvestris'ten 12 yumurta paketi ( $=84$ yumurta) olmak üzere toplam 88 yumurta paketi $(=679$ yumurta) incelenmiştir. Yumurta paketlerinin büyük bir çoğunluğunun (\%97) bir ibre üzerine bir yumurta paketi şeklinde bırakıldığ 1 gözlenmiş, bu nedenle bir ibre üzerine iki ve üç adet bırakılan yumurta paketleri değerlendirmeye alınmamıştır.

Pinus nigra ibrelerindeki bir yumurta paketinde yumurta say1sı arazide en az 2, en fazla 18 (ort. 7,94), laboratuvar koşullarında ise en az 1, en fazla 17 (ort. 7,81) olarak bulunmuştur. Buna göre yu- murta paketindeki yumurta sayısı her iki koşulda önemli bir farklılık göstermemiştir. Laboratuvar koşullarında $P$. sylvestris ibreleri üzerine bırakılan yumurta sayıs1 en az 3, en fazla 12 (ort. 7,00) olarak bulunmuş ve $P$. nigra ibrelerine birakılan yumurta sayısından az olduğu görülmüştür. Şekil 5 'te bir ibre üzerine birakılan iki yumurta paketi ve yumurtadan çıkan nimfler görülmektedir.

Yumurtaların açılma oranları ise $P$. nigra'da ortalama \%88,60 (arazi) ve \%81,47 (laboratuvar), $P$. sylvestris'te ortalama \%95,55 olarak bulunmuştur. P. nigra ibrelerindeki yumurtaların 13 (arazi) ve 40 (laboratuvar), P. sylvestris ibrelerindeki yumurtaların ise 10 (laboratuvar) yumurta paketindeki yumurtaların tamamı açılmıştır.

Türün yumurta bırakma davranışını ortaya koymak amaciyla arazi ve laboratuvarda elde edilen yumurtaların bırakıldığg ibre uzunluğu, yumurta

Tablo 6. Leptoglossus occidentalis'in arazide ve laboratuvardaki toplam yumurta sayısı ve yumurtaların açılma oranlar1 (ort.+sh) (n: yumurta paketi say1s1)

Tablo 6. The total number of eggs laid by Leptoglossus occidentalis and their hatching rates in the field and laboratory (mean.+se) (n: the number of egg mass)

\begin{tabular}{|c|c|c|c|c|c|c|c|c|c|}
\hline \multirow{2}{*}{ Parametreler } & \multicolumn{3}{|c|}{$\begin{array}{l}\text { Pinus nigra }(\mathrm{n}=17) \\
(\text { arazi })\end{array}$} & \multicolumn{3}{|c|}{$\begin{array}{l}\text { Pinus nigra }(\mathrm{n}=59) \\
\text { (lab.) }\end{array}$} & \multicolumn{3}{|c|}{$\begin{array}{c}\text { Pinus sylvestris }(\mathrm{n}=12) \\
\text { (lab.) }\end{array}$} \\
\hline & Ort. $( \pm$ Sh $)$ & Min. & Mak. & Ort. $( \pm$ Sh $)$ & Min. & Mak. & Ort. $( \pm \mathrm{Sh})$ & Min. & Mak. \\
\hline $\begin{array}{l}\text { Yumurta paketindeki } \\
\text { yumurta say1s1 }\end{array}$ & $7,94 \pm 0,90$ & 2 & 18 & $7,81 \pm 0,51$ & 1 & 17 & $7,00 \pm 0,83$ & 3 & 12 \\
\hline $\begin{array}{l}\text { Yumurtaların açılma } \\
\text { oranı }(\%)\end{array}$ & 88,60 & 45,45 & 100 & 81,47 & 0 & 100 & 95,55 & 66,66 & 100 \\
\hline
\end{tabular}



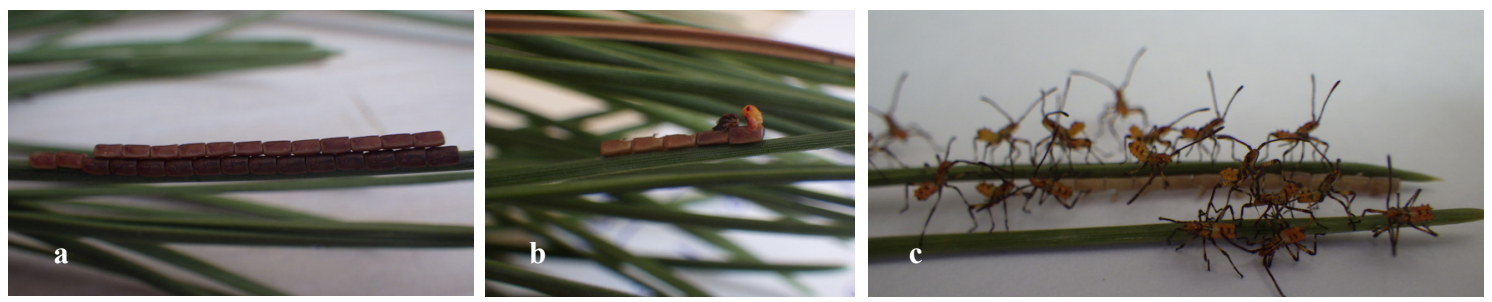

Şekil 5. Bir ibre üzerindeki iki yumurta paketi (a), yumurtadan yeni çıkan (b) ve çıkmış nimfleri (c) Figure 5. Two egg masses on a needle (a), newly hatching (b) and hatched nypmhs (c)

paketi uzunluğu ve yumurta paketlerinin ibre ucuna mesafesi ölçülmüş ve Tablo 7'de verilmiştir. Yumurtaların birakıldığı ibrelerin ortalama uzunluklarının $P$. nigra'da arazide $9,80 \mathrm{~cm}$, laboratuvarda $10,31 \mathrm{~cm}$ ve $P$. sylvestris'te 4,23 cm olduğu tespit edilmiştir. Yumurta paketinin ortalama uzunluklar1 P. nigra'da arazi örneklerinde $1,52 \mathrm{~cm}$, laboratuvar örneklerinde $1,49 \mathrm{~cm}$ ve $P$. sylvestris'te ise 1,35 $\mathrm{cm}$ bulunmuştur. Yumurtaların ibre ucuna olan ortalama mesafesi $P$. nigra'da arazi örneklerinde $2,68 \mathrm{~cm}$, laboratuvar örneklerinde $2,04 \mathrm{~cm}$ ve $P$. sylvestris'te ise $1,07 \mathrm{~cm}$ olarak ölçülmüştür. Arazi ve laboratuvar koşullarında $P$. nigra'da yumurtaların ibre ucuna mesafelerinin birbirine yakın olduğu görülmektedir. Yumurtaların çoğunlukla ibre ucuna yakın bırakıldığı görülmüştür (Şekil 6).

Tablo 7. Araziden toplanan ve laboratuvar koşullarında yumurtaların bırakıldığı ibre uzunluğu, yumurta paketi uzunluğu ve yumurtanın ibre ucuna mesafesi (ort. + sh) (n: yumurta paketi sayısı)

Table 7. Needle length, length of an egg mass, distance of egg mass from a needle apex, egg mass laid on a pine needle in laboratory and field (mean. + se) (n: the number of egg mass)

\begin{tabular}{|c|c|c|c|c|c|c|c|c|c|}
\hline \multirow{2}{*}{$\begin{array}{l}\text { Parametreler } \\
(\mathrm{cm})\end{array}$} & \multicolumn{3}{|c|}{$\begin{array}{l}\text { Pinus nigra }(\mathrm{n}=17) \\
(\text { arazi })\end{array}$} & \multicolumn{3}{|c|}{$\begin{array}{l}\text { Pinus nigra }(\mathrm{n}=59) \\
\text { (lab.) }\end{array}$} & \multicolumn{3}{|c|}{$\begin{array}{l}\text { Pinus sylvestris }(\mathrm{n}=12) \\
\text { (lab.) }\end{array}$} \\
\hline & Ort. ( $( \pm$ Sh) & Min. & Mak. & Ort. $( \pm$ Sh) & Min. & Mak. & Ort. ( \pm Sh) & Min. & Mak. \\
\hline İbre uzunluğu & $9,80 \pm 0,56$ & 4,70 & 13,70 & $10,31 \pm 0,29$ & 5,70 & 15,70 & $4,23 \pm 0,29$ & 2,70 & 5,60 \\
\hline Yums & $1,52 \pm 0,18$ & 0,70 & 3,37 & $1,49 \pm 0,10$ & 0,22 & 3,41 & $1,35 \pm 0,18$ & 0,40 & 2,10 \\
\hline Yumurtanın ibre ucuna mesafesi & $2,68 \pm 0,75$ & 0,10 & 9,20 & $2,04 \pm 0,27$ & 0,10 & 9,70 & $1,07 \pm 0,16$ & 0,20 & 1,80 \\
\hline
\end{tabular}

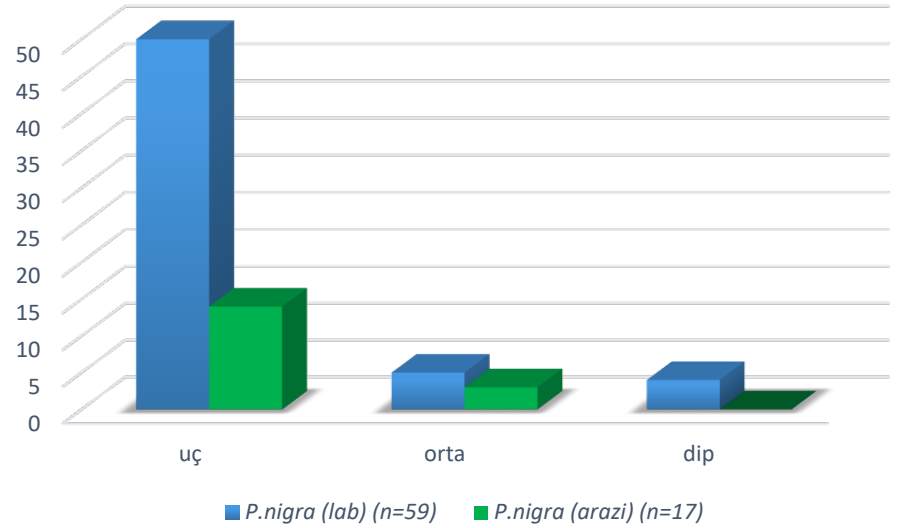

Şekil 6. Leptoglossus occidentalis'in laboratuvar ve arazi koşullarında Pinus nigra ibrelerine bırakılan yumurta paketlerinin ibre üzerindeki konumu

Figure 6. The position of egg masses of Leptoglossus occidentalis in Pinus nigra needles in laboratory and field

\subsection{Türün parazitoitleri}

Çalışmada Leptoglossus occidentalis'in yumurtalarından iki parazitoit türü elde edilmiş olup bu çalışma ile türün Türkiye'de ilk kez parazitoiti tespit edilmiştir.
Anastatus bifasciatus (Geoffroy, 1785) (Hymenoptera: Eupelmidae): Eğirdir-Pazarköy'de Pinus nigra üzerinden 06.10.2017 tarihinde toplanan yumurta paketinde iki adet açılmayan yumurtanın bir tanesinden 09.10.2017 tarihinde $A$. bifasciatus türüne ait bir adet parazitoit çıkışı olmuştur (Şekil 7). 
Ooencyrtus telenomicida (Vassiliev) (Hymenoptera: Encyrtidae): Yalvaç-Bahtiyar köyünde $P i$ nus nigra üzerinden 13.09.2017 tarihinde toplanan yumurta paketinde iki adet açılmayan yumurtanın bir tanesinden 19.09.2017 tarihinde O. telenomicida türüne ait üç adet parazitoit çıkışı olmuştur (Şekil 7).
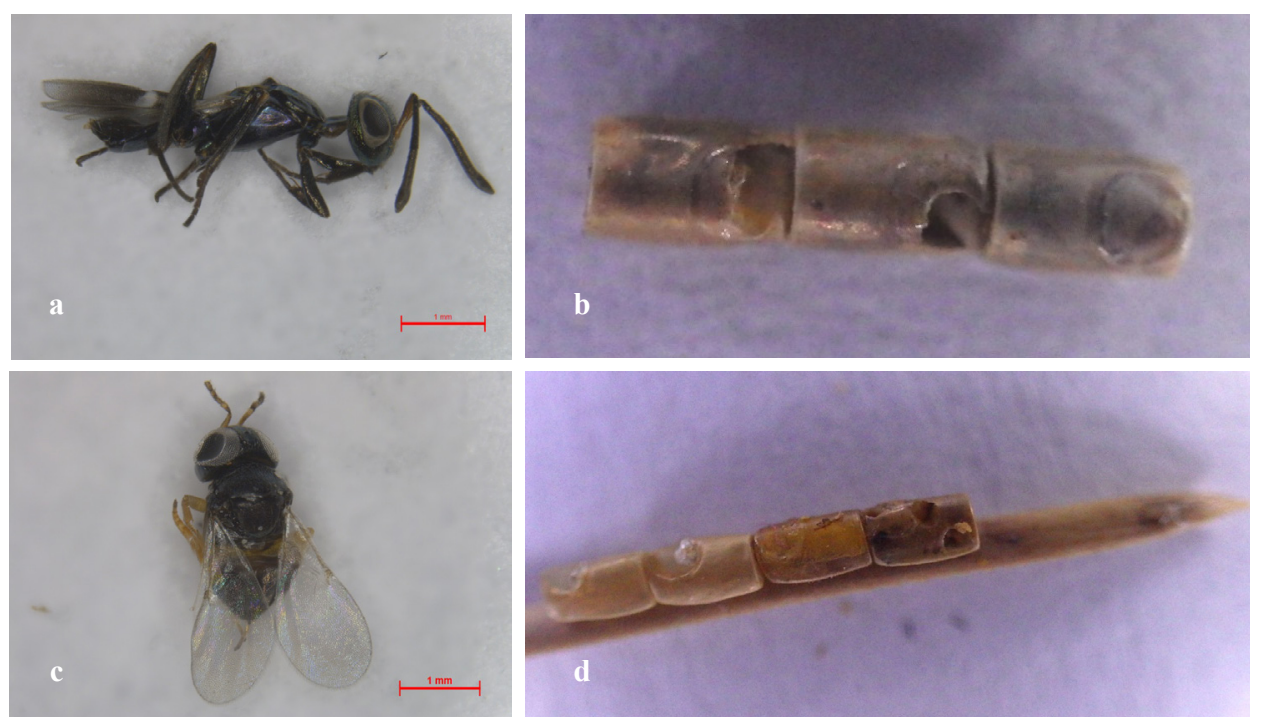

Şekil 7. Anastatus bifasciatus ergini (a) ve çıkış deliği (b), Ooencyrtus telenomicida ergini ve (c) çıkış deliği (d) Figure 7. Adult of Anastatus bifasciatus (a) and its exit holes (b), adult of Ooencyrtus telenomicida (c) and its exit holes (d)

\section{Tartışma ve Sonuç}

Leptoglossus occidentalis'in morfolojik özelliklerine dair bilgiler birçok çalışmada verilmiştir. Bu çalışmada vücut uzunluğu 15,10-21,80 mm arasında, dişilerde ortalama $19,10 \mathrm{~mm}$, erkeklerde ise ortalama 17,69 mm olarak ölçülmüştür. Koerber (1963), erginlerin vücut uzunluğunu $15-18 \mathrm{~mm}$, Villa ve ark. (2001) 16-20 mm, Fent ve Kment (2011) 15-20 mm, Dursun (2016) 20 mm, Özek ve Avc1 (2017) ise ortalama $20 \mathrm{~mm}$ olarak bulmuştur. Elde edilen vücut uzunlukları ile literatürde verilen uzunluklar büyük oranda uyumlu olmakla birlikte, bu çalişmada sekiz bireyde 20 mm'nin üzerinde vücut uzunluğu ölçülmüştür.

Ortalama proboscis uzunluğunun (dişilerde 12,00 $\mathrm{mm}$, erkeklerde ise $11,74 \mathrm{~mm}$ ) vücut uzunluğunda olduğu gibi erkeklerde dişilere oranla daha kısa olduğu belirlenmiştir. Özek ve Avcı (2017) proboscis uzunluğunun 12,5 mm olduğunu bildirmiştir. Bu değerin bu çalışmada elde edilen sonuçlara yakın olduğu görülmüştür. Koerber (1963) proboscisin üçüncü ve dördüncü abdominal segmentlere kadar ulaştığ1na, Dursun da (2016) proboscisin abdomenin ortalarına kadar uzandığına değinmiştir. Bu çalışmada da proboscis uzunluklarının hemen hemen abdomenin ortasında sonlandığı belirlenmiştir. Nimf dönemlerine ait elde edilen morfolojik özellikler Koerber'in (1963) tespitleriyle benzerlik göstermiştir.
Bu çalışmada söz konusu türün Batı Karadeniz'de Kastamonu, Güneydoğu Marmara'da Bilecik, İç Ege Bölgesi'nde Afyonkarahisar ve Batı Akdeniz'de Muğla/Fethiye'de tespit edildiği ve yayılışını hızla artırdığı, ülkemizdeki tespitinden bu yana yaklaşık 10 yıllık dönemde özellikle Batı Anadolu’ya yerleştiği görülmektedir.

Zararlının Kuzey Amerika'da yılda bir, Orta Amerika'da yılda üç, Avrupa'da ise 1-4 arasında generasyon verdiği bildirilmiştir (Bates ve Borden, 2005; Tamburini ve ark., 2012; Barta, 2016). Barta (2016) Slovakya'da türün yılda iki, Bernardinelli ve ark. (2006) İtalya'da laboratuvar koşullarında yılda üç, Tamburini ve ark. (2012) ise Kuzey İtalya'da türün yükseltiye bağlı olarak iki generasyon verdiğini, 220-390 m yükseltideki iki alanda yılda iki, 1040 $m$ yükseltideki alanda yılda bir generasyona sahip olduğunu belirtmiştir. Generasyon sayısındaki bu farklılığın ekolojik koşullar nedeniyle oluştuğu bildirilmiştir (Tamburini ve ark., 2012). Ülkemizde henüz biyolojisine dair bir çalışma bulunmadığından burada Avrupa'daki biyolojisi ile ilişkilendirilmiştir. Dört yıllık (2016, 2017, 2018 ve 2019) arazi gözlemleri sonucunda türün iki generasyona sahip olduğu ortaya konmuştur. İlk iki yıl (2016 ve 2017) tür ağustos ayından itibaren, üçüncü yıl (2018) haziran ayı sonundan itibaren, dördüncü yıl ise mayıs ortasından itibaren görülmeye başlanmış ve arazi gözlemlerinin yanı sıra 2018 yılında haziran ayında görülen 
erginler laboratuvara getirilerek ikinci generasyon dönemi takip edilmiştir. Slovakya'daki çalışmaya göre biyolojik dönemlerin ülkemizdekinden yaklaşık üç hafta daha önce olduğu görülmüştür. İlk generasyona ait erginlerin temmuz ortasından sonra görüldüğü, ikinci generasyonun ertesi sene tamamlandığ 1 , son dönem nimflerin ya da erginlerin kışı geçirip kışlaklardan mart ortasında çıkmaya başladığ1 bildirilmiştir (Barta, 2016). Çalışmamızda doğada kışlaklardan çıkan ilk erginler 12 Mayıs 2019 tarihinde görülmüştür.

Barta (2016) tarafından ilk generasyona ait nimflerin (1. nimf: 6,68, 2. nimf: 9.36, 3. nimf: 11,68, 4. nimf: 14.84, 5. nimf: 10,62) yaşam süreleri verilmiştir. Bu çalışmada ikinci generasyona ait veriler elde edildiğinden, bu verilerle kıyaslama yapıldığında bulgularımıza göre ikinci, üçüncü ve dördüncü nimf döneminin daha kısa, birinci ve beşinci nimf dönemlerinin ise daha uzun olduğu görülmüştür. Ayrıca Barta (2016) yaşam dönemlerinin ilk görüldüğü tarihleri vermiş ve bu çalışmadaki bulgulara göre ilk görülme tarihlerinin üç hafta daha erken olduğu görülmüştür. Bu durumun, ekolojik özelliklerin etkisinden kaynaklandığı söylenebilir.

$\mathrm{Bu}$ çalışmada toplam 88 yumurta paketi (=679 yumurta) incelenmiş, $P$. nigra'da bir yumurta paketindeki ortalama yumurta say1s1 arazide 7,94, laboratuvarda 7,81 ve $P$. sylvestris'te 7,00 olarak bulunmuş, yumurtaların ortalama \%84,77'sinin açıldığı, yumurta paketlerinin \%97'sinin ibrenin uç kısmına bırakıldığı gözlenmiştir. Slovakya'da Pinus armandii'de ortalama bir yumurta paketindeki yumurta sayısının 7,82 olduğu, yumurta paketlerinin \%86,49'unun ibrenin uç kısmına b1rakıldığı belirtilmiştir (Barta, 2016). Kanada'nın Britanya Kolombiyası'nda Pinus contorta'daki yumurtaların \%83,4'ünün açıldığı belirtilmiştir (Bates ve Borden, 2005).

Bu çalışma ile ülkemizde ilk kez türün parazitoitleri [Anastatus bifasciatus (Geoffroy, 1785) (Hymenoptera: Eupelmidae) ve Ooencyrtus telenomicida (Vassiliev) (Hymenoptera: Encyrtidae)] belirlenmiştir. A. bifasciatus, L. occidentalis'in parazitoiti olarak İtalya'da (Camponogara ve ark., 2003'e atfen Rabitsch ve Heiss, 2005) tespit edilmiş, ayrıca Hemiptera takımından Coreidae ve Pentatomidae, Lepidoptera takımından ise Cossidae, Erebidae, Sphingidae, Saturnidae, Lasiocampidae ve Notodontidae familyalarına bağlı türlerin parazitoiti olduğu bildirilmiştir (Ghahari ve ark., 2010; Stahl ve ark., 2018). Ülkemizde tespit edilen konukçular1 arasında Thaumetopoea wilkinsoni (Avc1, 2000; Can ve Özçankaya, 2002; Mirchev ve ark., 2004; Sar1kaya, 2004; Avc1 ve Ölmez, 2016), Lymantria dispar (Avc1, 2009), T. pityocampa (Şimşek ve ark.,
2017) ve Malacosoma neustria (Özbek ve Çoruh, 2010) türleri bulunmaktadır.

Ooencyrtus telenomicida, L. occidentalis'in parazitoiti olarak ilk kez tespit edilmiştir. $\mathrm{Bu}$ tür Hemiptera (Pentatomidae, Scutelleridae, Pyrrhocoridae, Reduviidae ve Coreidae) ve Lepidoptera takımından (Lasiocampidae, Sphingidae ve Erebidae) birçok familyaya ait türlerin yumurta parazitoitidir (Zhang ve ark., 2005; Samra ve ark., 2018). Bu türün, Nezara viridula ve Aelia spp. gibi zararlıların parazitoiti olduğu (Peri ve ark., 2011), Halyomorpha halys (Stål) ve Graphosoma lineatum L. (Heteroptera: Pentatomidae) türleri için biyolojik ajan (Roversi ve ark., 2018) olarak kullanılabileceği belirtilmiştir. Ülkemizdeki konukçuları Stenozygum coloratum (Samra ve ark., 2015), Eurygaster intergricepa ile Aelia rostrata'dır (Tuatay ve ark., 1972 ve Lodos, 1982'ye atfen Öncüer, 1991). Ayrıca tür, Isparta ve Yalvaç'ta Pentatomidae familyasından türlerin yumurta parazitoiti olarak tespit edilmiştir (Japoshvili ve Noyes, 2005). Bu parazitoit 1lıman iklim koşullarında bulunmakta ve ekstrem iklim koşullarında görülmemektedir (Samra ve ark., 2015).

Zararlının daha çok ormanlarımızın büyük bir kısmını oluşturan çam türleri ile kısmen göknar türlerinde görülmesi ülkemiz için önemini ortaya koymaktadır. L. occidentalis'in ülkemizde özellikle fistık çamındaki (Pinus pinea) zararı ekonomik önem taşımaktadır. Fistık çamında son yıllarda görülen verim düşüklüğünün sebepleri bazı çalışmalarda araştırılmış, bitki besin elementi eksikliği ya da meteorolojik değişimler olabileceği düşünülmüş, bazı çalışmalarda da böceğin önemli zarara yol açtığı bildirilmiştir. Türün tohumlarda önemli zarara yol açtığı bilinmektedir. Özellikle fıstık çamındaki zararının yanı sıra ibreli ağaç türlerinin tohum meşcereleri ve bahçelerinin sağlığ 1 ile doğal gençleştirme başarısını azaltması, ayrıca türün tohum verimini düşürmesi nedeniyle fidan üretiminde de sorunlara yol açması muhtemeldir. İklim değişimi ile birlikte yayılışını ve popülasyonunu artırması durumunda türle mücadele etmek daha zor hâle gelebilir. Türün beslenme davranış1, hızlı hareket etmesi, uzun mesafelere uçma kabiliyeti, feromonunun etkili olmaması gibi özellikleri nedeniyle biyolojik mücadele en makul mücadele yöntemi olarak düşünebilir.

Leptoglossus occidentalis ile mücadelede parazitoitlerin kullanımının gelecekte önemli olacağı kuvvetle muhtemeldir. Türün Türkiye'de ilk kez yerli parazitoitleri tespit edilmiştir. ABD ve Kanada'da Gryon pennsylvanicum (Ashmead) (Hymenoptera: Platygastridae) türünün etkili olduğu bildirilmiştir (Bates ve Borden, 2004). İtalya'da da türün yerli 
parazitoitleri tespit edilmiş ancak etkinliği düşük olduğu için $G$. pensylvanicum türünün getirilerek laboratuvar koşullardaki etkinliği üzerine çalışmalar yapılmıştır (Roversi ve ark., 2011; Maltese ve ark., 2012; Peverieri ve ark., 2012; Roversi ve ark., 2014). Ancak türün doğaya salınımı ile ilgili bir bilgiye rastlanmamıştır. Dolayısıyla tür ile mücadelede henüz bir biyolojik unsur bulunmamaktadır. Bu çalışmada tespit edilen parazitoit türlerin başka zararlıların da parazitoiti olması nedeniyle $L$. occidentalis için bu türlerin kullanımı üzerine daha fazla çalışma yapılması gerekmektedir. Özellikle türe özgü olan parazitoit türlerle daha etkin bir mücadele yapilabilir.

Dünyada olduğu gibi ülkemizde de türün hızla yayılması ve konukçularının ülkemizde en fazla yayılış yapan orman ağaçları arasında yer alması nedeniyle bu yabancı istilacı türün öncelikle dağılımı ile biyolojisinin farklı bölgeler ve ekolojik koşullar açısından belirlenmesi ve türle mücadele için gerekli verilerin ortaya konması gereklidir. Bu çalışmanın, ülkemizde de hızla yayılan ve çam türleri ve özellikle fıstık çamı kozalaklarında zarara neden olan türle mücadele çalışmalarına katkı sağlayacağ1 düşünülmektedir.

\section{Teșekkür}

Parazitoit türlerin teşhisi için Prof. George JAPOSHVILI'ye (Tiflis Tarım Üniversitesi, Entomoloji Enstitüsü, Gürcistan) teşekkür ederiz. Bu çalışmanın bir kısmı III. Türkiye Orman Entomolojisi ve Patolojisi Sempozyumu'nda (Artvin, 10-12 May1s 2018) sunulmuş, bildiri kitabında özet olarak basılmıştır.

\section{Kaynaklar}

Aksu, Y., 2018. Leptoglossus occidentalis. [Erişim tarihi: 20.03.2019.] Erişim adresi: http://www.yasaraksu. com/icerik.asp?sayfa $=22$

Arslangündoğdu, Z., Hızal, E., 2010. The Western Conifer Seed Bug, Leptoglossus occidentalis (Heidemann, 1910), recorded in Turkey (Heteroptera: Coreidae). Zoology in the Middle East, 50(1), 138-139.

Avc1, M., 2000. Investigations on structure of egg-batches, parasitism and egg laying habits of Thaumetopoea pityocampa (Den. \& Schiff.) (Lep.: Thaumetopoeidae) in various regions of Turkey. Türkiye Entomoloji Dergisi, 24(3), 167-178.

Avc1, M., 2009. Parasitoid complex and new host plants of the gypsy moth, Lymantria dispar L. in the Lakes District, Turkey. Journal of Animal and Veterinary Advances, 8, 1402-1405.

Avc1, M., Ölmez, S. G., 2016. Isparta çam ormanlarında doğu çam kese böceği Thaumetopoea wilkinsoni
Tams, 1924 (Lepidoptera: Notodontidae)'nin yumurta koyma şekli ve yumurta koçanlarının yapısı. İstanbul Üniversitesi, Orman Fakültesi Dergisi, 66(2): 613-627.

Barclay, M., Nikolaeva, S., 2018. Arrival in Kazakhstan of Leptoglossus occidentalis (Hemiptera: Heteroptera: Coreidae); a North American invasive species expands 2,500 kilometres to the east. Klapalekiana, 54: 1-3, 2018.

Barta, M., 2009. New facts about distribution and host spectrum of the invasive Nearctic conifer pest, Leptoglossus occidentalis (Heteroptera: Coreidae) in southwestern Slovakia. Folia Faunistica Slovaca, 14(23), 139-142.

Barta, M., 2016. Biology and temperature requirements of the invasive seed bug Leptoglossus occidentalis (Heteroptera: Coreidae) in Europe. J Pest Sci, 89:31-44.

Bates, S. L., Borden, J. H. 2004. Parasitoids of Leptoglossus occidentalis Heidemann (Heteroptera: Coreidae) in British Columbia. Journal of the Entomological Society of British Columbia, 101:143-144.

Bates S. L., Borden J. H., 2005. Life table for Leptoglossus occidentalis (Heteroptera: Coreidae) and prediction of damage in lodgepole pine seed orchards. Agricultural and Forest Entomology, 7:145-151.

Bates, S. L., Borden, J. H., Kermode, A. R., Bennett, R. G., 2000. Impact of Leptoglossus occidentalis (Hemiptera: Coreidae) on Douglas-fir seed production. Journal of Economic Entomology, 93(5), 1444-1451.

Bates, S. L., Strong, W. B., Borden, J. H., 2002. Abortion and seed set in lodgepole and western white pine conelets following feeding by Leptoglossus occidentalis (Heteroptera: Coreidae). Environmental Entomology, 31(6), 1023-1029.

Ben Jamâa, M., Mejri, M., Naves, P., Sousa, E., 2013. Detection of Leptoglossus occidentalis Heidemann, 1910 (Heteroptera: Coreidae) in Tunisia. African Entomology, 21(1), 165-168.

Bernardinelli, I., Rovato, M., Zandigiacomo, P., 2006. Life history and laboratory rearing of Leptoglossus occidentalis. In: Forster B, Kn1 'žek M, Grodzki W, (eds) Methodology of forest insect and disease survey in central Europe. IUFRO 7.03.10, Proceedings of the Workshop, 11-14 September 2006, Gmunden, Austria.

Camponogara, P., M. Festi, Battisti, A., 2003. La cimice dei semi americana: un ospite indesiderato delle conifere. Vita in Campagna, 7-8.

Can, P., Özçankaya, İ. M., 2002. Ege Bölgesi ağaçlandırma alanlarında Çam keseböceği (Thaumetopoea pityocampa (Den. \& Schiff.) yumurta parazitoidlerinin belirlenmesi. Ege Ormancılık Araştırma Müdürlüğü, Teknik Bülten Serisi: 22.

Çerçi, B., Koçak, Ö., 2016. Contribution to the knowledge of Heteroptera (Hemiptera) fauna of Turkey. Journal of Insect Biodiversity, 4(15), 1-18, 2016.

Dursun, G., 2016. Balıkesir kent ormanı ve BAUN Çağış 
yerleşkesindeki Heteroptera (Hemiptera) faunasının kışlak tuzaklarla belirlenmesi üzerinde araştırmalar. Yüksek Lisans Tezi, Balıkesir Üniversitesi, Fen Bilimleri Enstitüsü, Balıkesir.

Faúndez, E. I., Rocca, J. R., Villablanca, J., 2017. Detection of the invasive western conifer seed bug Leptoglossus occidentalis Heidemann, 1910 (Heteroptera: Coreidae: Coreinae) in Chile. Arquivos Entomolóxicos, (17), 317-320.

Fent, M., Kment, P., 2011. First record of the invasive western conifer seed bug Leptoglossus occidentalis (Heteroptera: Coreidae) in Turkey. North-Western Journal of Zoology, 7 (1): 72-80.

Gall, W. K., 1992. Further eastern range extension and host records for Leptoglossus occidentalis (Heteroptera: Coreidae): well-documented dispersal of a household nuisance. The Great Lakes Entomologist, 25(3), 159-171.

Gapon, D. A., 2013. First records of the western conifer seed bug Leptoglossus occidentalis Heid.(Heteroptera, Coreidae) from Russia and Ukraine, regularities in its distribution and possibilities of its range expansion in the palaearctic region. Entomological Review, 93(2), 174-181.

Gapon, D. A., 2015. First record of Leptoglossus occidentalis (Heteroptera: Coreidae) in Morocco. Heteropterus Rev Entomology, 15, 161-163.

Ghahari, H., Erdogan, O. C., Sedivy, J., Ostovan, H., 2010. Survey of the Ichneumonoidea and Chalcidoidea (Hymenoptera) parasitoids of Saturnidae (Lepidoptera) in Iran. Efflatounia, 10, 1-6.

Heidemann, O., 1910. New species of Leptoglossus from North America Hemiptera: Coreidae). Proceedings of the Entomological Society of Washington, 12: 191-197.

Hizal E., İnan M., 2012. Leptoglossus occidentalis (Heidemann, 1910) is an invasive insect species. Journal of The Bartın Faculty of Forestry, 14: 56-61.

H1zal, E., 2012. Two invasive alien insect species, Leptoglossus occidentalis (Heteroptera: Coreidae) and $C y$ dalima perspectalis (Lepidoptera: Crambidae), and their distribution and host plants in Istanbul. Florida Entomologist, 95(2): 344-349.

Ishikawa, T., Kikuhara, Y., 2009. Leptoglossus occidentalis Heidemann (Hemiptera: Coreidae), a presumable recent invader to Japan. Japanese Journal of Entomology, 12(3), 115-116.

Japoshvili, G. O., Noyes, J. S., 2005. Checklist and new data on Encyrtidae of Transcaucasia and Turkey (Hymenoptera: Chalcidoidea). Zoosystematica Rossica, 14(1), 135-145.

Kment, P., Banar, P., 2008. Additional records of the invasive Nearctic bug Leptoglossus occidentalis (Heteroptera: Coreidae) in Croatia. Natura Croatica, 17(2), 141.

Koerber, T. W., 1963. Leptoglossus occidentalis (Hemiptera, Coreidae), a newly discovered pest of coniferous seed. Annals of the Entomological Society of America, 56(2), 229-234.
Kollár, J., HrubíK, P., TKáčoVá, S., 2009. Monitoring of harmful insect species in urban conditions in selected model areas of Slovakia. Plant Protection Science, 45(3), 119-124.

Maltese, M., Caleca, V., Carapezza, A., 2009. Primi reperti in Sicilia su diffusione e biologia di Leptoglossus occidentalis Heidemann (Hetroptera: Coreidae), cimice americana dei semi delle conifere. In Congresso Nazionale di Selvicoltura (Vol. 3, pp. 1413-1418). IT.

Maltese, M., Caleca, V., Guerrieri, E., Strong, W.B., 2012. Parasitoids of Leptoglossus occidentalis Heidemann (Heteroptera: Coreidae) recovered in western North America and first record of its egg parasitoid Gryon pennsylvanicum (Ashmead) (Hymenoptera: Platygastridae) in California. Pan-Pac. Entomol., 188, 347-355.

Mirchev, P., Schmidt, G. H., Tsankov, G., Avci, M., 2004. Egg parasitoids of Thaumetopoea pityocampa (Den. \& Schiff.) (Lep., Thaumetopoeidae) and their impact in SW Turkey. Journal of Applied Entomology, 128(8), 533-542.

Nemer, N., 2015. Report on insect pests associated with conelet losses and their management in Pinus pinea forests in Lebanon. FAO, Rome 45 pp.

Oğuzoğlu, Ş., Avcı, M., 2018. Isparta ve Burdur İllerinde Leptoglossus occidentalis Heidemann, 1910 (Hemiptera: Coreidae)'e Ait Gözlemler ve Türkiye'deki Durumu. III. Türkiye Orman Entomolojisi ve Patolojisi Sempozyumu Bildiri Özetleri, 10-12 May1s, Artvin, 13-14.

Öncüer, C., 1991. A catalogue of the parasites and predators of insect pests of Turkey. pp.208.

Özbek, H., Çoruh, S., 2010. Egg parasitoids of Malacosoma neustria (Linnaeus, 1758) (Lepidoptera: Lasiocampidae) in Erzurum province of Turkey. Türk Entomol Derg, 34, 551-560.

Özek, T., Avc1, M., 2017. Isparta Orman Bölge Müdürlüğü göknar, çam ve sedir ormanlarında tespit edilen kozalak zararlıları. Turkish Journal of Forestry, 18(3): 178-186.

Özgen, İ., Dioli, P., Çelik, V., 2017. New and interesting record of western conifer seed bug: Leptoglossus occidentalis (Heidemann, 1910) (Heteroptera: Coreidae) in Eastern Turkey. Journal of Entomology and Zoology Studies, 5(5): 830-833.

Parlak, S., 2017. An invasive species: Leptoglossus occidentalis (Heidemann) how does it affect forestry activities? Kastamonu Univ., Journal of Forestry Faculty, 2017, 17 (3): 531-542.

Peri, E., Cusumano, A., Agro,' A., Colazza, S., 2011. Behavioral response of the egg parasitoid Ooencyrtus telenomicida to host-related chemical cues in a tritrophic perspective. BioControl, 56: 163-171.

Petrakis, P. V., 2011. First record of Leptoglossus occidentalis (Heteroptera: Coreidae) in Greece. Entomologia Hellenica, 20(2), 83-93.

Peverieri, G. S., Furlan, P., Simoni, S., Strong, W.B., Roversi, P.F., 2012. Laboratory evaluation of Gryon penn- 
sylvanicum (Ashmead) (Hymenoptera, Platygastridae) as a biological control agent of Leptoglossus occidentalis Heidemann (Heteroptera, Coreidae). Biol. Control 61, 104-111.

Pimpao, M., Valdiviesso, T., Trindade, C.S., Naves, P., Sousa, E., 2017. Leptoglossus occidentalis damages on stone pine female reproductive structures. In: CarrasquinhoI. (ed.), Correia A.C. (ed.), Mutke S. (ed.). Mediterranean pine nuts from forests and plantations. Zaragoza: CIHEAM, 2017, 85-89.

Protic, L., 2008. Leptoglossus occidentalis Heidemann (Heteroptera: Coreidae) in Serbia. Acta Entomol. Serbica, 13, 81-84

Putshkov, P. V., Gubin, A. I., Popov, G. V., Kalesnik, V. I., Syzhko, V. V., 2012. The North American intruder Leptoglossus occidentalis Heidemann (Heteroptera: Coreidae) settled down in Ukraine. Українська ентомофауністика, 3(3), 1-3.

Rabitsch, W., Heiss, E., 2005. Leptoglossus occidentalis Heidemann, 1910, eine amerikanische Adventivart auch in Österreich aufgefunden (Heteroptera, Coreidae). $\mathrm{Be}$ richte des naturwissenschaftlichmedizinischen Verein Innsbruck, 92, 131-135.

Roversi, P.F., Strong, W.B., Caleca, V., Maltese, M., Sabbatini Peverieri, G,, Marianelli, L., Marziali, L., Strangi, A., 2011. Introduction into Italy of Gryon pennsylvanicum (Ashmead), an egg parasitoid of the alien invasive bug Leptoglossus occidentalis Heidemann. EPPO Bulletin, 41, 72-75.

Roversi, P. F., Sabbatini Peverieri, G., Maltese, M., Furlan, P., Strong, W. B., Caleca, V. 2014. Pre-release risk assessment of the egg-parasitoid Gryon pennsylvanicum for classical biological control of Leptoglossus occidentalis. Journal of Applied Entomology, 138(1-2): 27-35.

Roversi, P. F., Maltese, M., Simoni, S., Cascone, P., Binazzi, F., Strangi, A., Peverieri, G.,S., Guerrieri, E., 2018. Graphosoma lineatum (Hemiptera: Pentatomidae): a suitable host for mass rearing Ooencyrtus telenomicida (Hymenoptera: Encyrtidae). International Journal of Pest Management, 64(4): 294-302.

Samra, S., Cascone, P., Noyes, J., Ghanim, M., Protasov, A., Guerrieri, E., Mendel, Z., 2018. Diversity of Ooencyrtus spp. (Hymenoptera: Encyrtidae) parasitizing the eggs of Stenozygum coloratum (Klug) (Hemiptera: Pentatomidae) with description of two new species. PloS One, 13(11), e0205245.

Samra, S., Ghanim, M., Protasov, A., Mendel, Z., 2015. Spatial distribution and niche partitioning in the Ooencyrtus spp. complex parasitizing the eggs of Stenozygum coloratum. BioControl, 60(6), 747-760.

Sarkkaya, O., 2004. Isparta Yöresinde Thaumetopoea pityocampa (Den. \& Schiff.) (Lep.: Thaumetopoeidae)'nın Yumurta Koçanları Üzerine Araştırmalar, SDÜ Orman Fakültesi Dergisi, Seri: A, $1,1-11$.
Schoettle, A. W., Negron, J. F., 2001. First report of two cone and seed insects on Pinus flexilis. Western North American Naturalist, 61(2), 252-254.

Şimşek, Z., Kondur, Y., Yurt, E., 2017. Çankırı (Eldivan) Karaçam Ormanlarında Bulunan Çam Keseböceği [Thaumetopoea pityocampa (Den. \&Schiff.) (Lepidoptera: Thaumetopoeidae)]'nin Yumurta Parazitoitlerinin Tespiti ile Etkinliği Üzerinde Araştırmalar. Anadolu Orman Araştırmaları Dergisi, 3(2), 210-218.

Stahl, J. M., Babendreier, D., Haye, T. 2018. Using the egg parasitoid Anastatus bifasciatus against the invasive brown marmorated stink bug in Europe: can non-target effects be ruled out?. Journal of Pest Science, 91(3), 1005-1017.

Strong, W. B., 2006. Seasonal changes in seed reduction in lodgepole pine cones caused by feeding of Leptoglossus occidentalis (Hemiptera: Coreidae). The Canadian Entomologist, 138(6), 888-896.

Tamburini, M., Maresi, G., Salvador,i C., Battisti, A., Zottele, F., Pedrazzoli, F., 2012. Adaptation of the invasive western conifer seed bug "Leptoglossus occidentalis to Trentino, an alpine region (Italy). Bulletin of Insectology, 65:161-170

Van der Heyden, T., 2018. First record of Leptoglossus occidentalis Heidemann (Heteroptera: Coreidae: Coreinae: Anisoscelini) in Albania. Revista Chilena de Entomología, 44(3).

Vanin, S., Uliana, M., Bonato, L., Maistrello, L., 2005. Nuove segnalazioni di Leptoglossus occidentalis (Heteroptera, Coreidae) nell'Italia nord-orientale. Società Veneziana di Scienze Naturali, Lavori 30: 149.

Villa, M., Tescari, G., Taylor, S. J., 2001. Nuovi dati sulla presenza in Italia di Leptoglossus occidentalis. Boll. Soc. Entomol. Ital, 133(2), 103-112.

Y1ldırım, E., Yazıc1, G., Moulet, P., 2013. Contribution to the knowledge of the Gerridae, Coreoidea, Piesmatidae, Saldidae, Corixoidea, Nepoidea and Notonectidae (Hemiptera, Heteroptera) fauna of Turkey. Linzer biol. Beitr., 45(1), 995-1010.

Yoon, C. S., Kim, H. G., Park, J. D., Choi, W. Y., Choi, H. J., Cheong, S. W., 2012. First record of the Western Conifer Seed Bug, Leptoglossus occidentalis Heidemann (Heteroptera: Coreidae) in Korea. Journal of Environmental Science International, 21(8), 1009-1013.

Zhang, Y. Z., Li, W., Huang, D. W., 2005. A taxonomic study of Chinese species of Ooencyrtus (Insecta: Hymenoptera: Encyrtidae). Zoological Studies-Taipei, 44(3), 347.

Zhu, G. P., Rédei, D., Kment, P., Bu, W. J., 2014. Effect of geographic background and equilibrium state on niche model transferability: predicting areas of invasion of Leptoglossus occidentalis. Biological Invasions, 16(5), 1069-1081. 